\title{
Food deprivation and conditioned reinforcing value of food words: Interaction of Pavlovian and instrumental conditioning
}

\author{
JOAN Y. HARMS and ARTHUR W. STAATS \\ University of Hawaii, Honolulu, Hawaii 96822
}

\begin{abstract}
Food words are conditioned stimuli for an emotional response (salivation). According to the theory relating classical and instrumental conditioning, food words should serve as reinforcing stimuli in instrumental conditioning, more so under food deprivation than under satiation. The reinforcement property of food words was demonstrated with subjects under food deprivation (1) supporting the three-function learning theory relating Pavlovian and instrumental conditioning, (2) stipulating general motivational principles, and (3) indicating the emotionalmotivational principles of language.
\end{abstract}

Reinforcement is a concept central to learning theory and behavioristic accounts of animal and human behavior. According to Hull (1943), the reinforcement value of a stimulus was due to the drive-reduction value of the stimulus. In Skinner's learning theory (Holland \& Skinner, 1961; Skinner, 1938), reinforcement value was defined solely by its ability to perform the responsestrengthening function. It has been suggested in a threefunction learning theory (Staats, 1968) that the reinforcing value of a stimulus depends on the stimulus eliciting an emotional response.

According to this two-process approach, a stimulus that functions in classical (Pavlovian) conditioning as an unconditioned stimulus (UCS) or conditioned stimulus (CS) to elicit an emotional response will, as a consequence, also have reinforcing value in instrumental conditioning. This three-function theory has also indicated that in the mature organism, through learning, a stimulus that is a CS for an emotional response and hence can be a reinforcing stimulus will also function as a directive (discriminative) stimulus and control either approach instrumental responses (in the positive case) or avoidance responses (in the negative case) (Staats, 1975). There are a number of studies on the animal level (e.g., Brown \& Jenkins, 1968; Trapold \& Winokur, 1967; Zimmerman, 1957) that can be interpreted and integrated with the three-function learning theory (Staats, 1975; Staats \& Warren, 1974), as well as a number of studies on the human level (Staats, 1975).

To directly demonstrate the principles on the human level, it was necessary to have stimuli that as CSs elicited an emotional response. The stimuli selected were food words, on the assumption that natural pairing of

This experiment was done by the first author as part of a doctoral dissertation at the University of Hawaii under the supervision of the second author. Requests for reprints should be sent to Arthur W. Staats, Department of Psychology, 2430 Campus Road, Honolulu, Hawaii 96822. food with food words would produce the classical conditioning of a positive emotional response to food words. One study showed this to be the case, in that food-deprived subjects salivated more to food words than did nondeprived subjects (Staats \& Hammond, 1972). Finch (1938) had previously shown that fooddeprived dogs salivated more to a CS. Staats, Minke, Martin, and Higa (1972) showed the food words could transfer the conditioned emotional response to a neutral stimulus, in a classical conditioning procedure, more strongly for food-deprived subjects than for nondeprived subjects. Staats and Warren (1974) showed that fooddeprived subjects could learn an approach response to food words as the directive (discriminative) stimulus in a two-choice response task more rapidly than they could learn an avoidance response, and that such subjects learned an approach response to food words more rapidly than did nondeprived subjects.

The last expectation of this three-function learning theory in this basic context is that food words, since they are CSs for an emotional response, can serve as reinforcing stimuli in learning an instrumental response. The reinforcement effect should be stronger for fooddeprived subjects than for nondeprived subjects, the present hypothesis.

\section{METHOD}

\section{Subjects}

Subjects were 176 volunteer, native English-speaking, undergraduate educational psychology students of the University of Hawaii. Subjects were recruited from 16 sections of courses, treated as intact groups, and randomly assigned to the experimental or control group.

\section{Apparatus}

The operant conditioning apparatus was similar to the one employed by Finley and Staats (1967). The apparatus was placed on a rectangular table in a $2.44 \times 3.05$ m experimental room. The subject faced a $61 \times 76 \mathrm{~cm}$ wooden partition with a 
red signal light mounted at eye level and a response button for the right hand and one for the left hand. A cassette player on which the experimental directions were played was situated to the right of the subject. On the other side of the partition, the experimenter faced two signal lights, each one activated by one of the subject's response buttons, as well as a switch controlling the onset of the red signal light. Two pieces of sham equipment, observable to the subject, gave the appearance of a galvanic skin response (GSR) apparatus. These were employed to substantiate the cover story.

\section{Materials}

Thirty-six food words (e.g., lobster, stew, and bacon) had been obtained from a previous study concerning deprivationsatiation conditions and the strength of attitude conditioning (Staats et al., 1972). Fifty neutral words had been selected from Wilcox and Pollio (Note 1) on the basis of a mean 7-point pleasant-unpleasant rating of 4.02 scale with college students. All words were randomly ordered and typed on $6 \times 8 \mathrm{~cm}$ cards.

\section{Procedure}

During the recruitment of subjects, the deprived group was asked to eat nothing and drink no nutritive liquids from bed time the night before the experiment until the next day's experimental appointment time. The nondeprived group was asked to eat a full meal within $1 \mathrm{~h}$ prior to their experimental appointment. All subjects were questioned as to the medical feasibility of the eating plan and whether they were native English speakers. Before the experiment, subjects individually listened to taped instructions concerning the experimental procedures. GSR electrodes were placed on the subject's palms. Subjects were told the purpose of the experiment was to measure their physiological responses to words while they were involved in a standardized button-pushing task.

During the conditioning phase, each trial consisted of the onset of the red signal light. The subject's task was to turn out the light by pressing either one of the two buttons, not with any special haste. Following the subject's response, the experimenter pronounced a word, using the same tone for all words, and the subject repeated the word. The experimenter presented a series of 60 such trials, which were partitioned into six blocks of 10 trials each. The first block represented a preconditioning period, when neutral words were verbally presented to all subjects regardless of right or left button-push responses. These neutral words were not reused in the remaining five blocks. Subjects who responded on either button continuously for the first or second block of trials were eliminated from the study.

Response-contingent reinforcement began during the second block. Left button-push responses were followed by auditory presentation of a food word; right button-push responses were followed by neutral nonfood words. The experimenter was blind to the deprivation state of the subjects. Following conditioning, subjects were asked to "write down your impressions of the experiment while it was being conducted," and to "write down what you felt was the purpose of the experiment." Subjects also indicated how long it had been since they had eaten, as well as how hungry they were (on a 7-point hungry-full rating scale).

\section{RESULTS}

The basic design was a one-between one-within factorial, repeated over six blocks of trials. Factor A was deprivation and Factor B was the six blocks of conditioning trials. The experimental and control groups were comparable on the first block of trials. The learning curves of mean left-hand responses for the deprivation groups showed that in both cases left-hand responses were made slightly less than $50 \%$ of the time. From that point on, the left-hand response was gradually strengthened in the food-deprived group. In the nondeprived group, the strength of the left-hand response remained about the same, with some fluctuation.

An analysis of variance was performed on the conditioning data. the results indicated a significant groups effect $[F(1,174)=6.01, p<.05]$ and a significant Groups by Blocks interaction effect $[F(5,870)=2.29$, $p<.05]$. The first of these results showed that the food words had a stronger effect in increasing the reinforced response for the deprived subjects than was the case for the nondeprived subjects. The second result indicated that there was a stronger effect over the blocks of trials for the deprived subjects than for the nondeprived subjects. A trend analysis did not show significant differences in linear trend for the two groups. A separate linear trend analysis was performed on each of the two groups against a slope of zero. The results indicated a significant linear trend for the experimental group $[F(1,435)=6.61, p<.05]$ and nonsignificant results for the control group. Thus, the curve of the deprived subjects indicated that the reinforced response became increasingly strong over the blocks of conditioning trials. This effect was not shown with the nondeprived subjects.

The mean hours of deprivation for the deprived group was 15.79 with a standard deviation of 3.07 ; the mean hours of deprivation for the nondeprived group was .88 with a standard deviation of .45 . The deprived group mean hunger rating on a 1-7 hungry-full scale was 2.70 with a standard deviation of 1.35 , and for the nondeprived group the mean hunger rating was 5.48 with a standard deviation of 1.18 .

The awareness data were analyzed by means of a seven-category rating scale modeled after an earlier study involving button-press responses (Staats, Higa, \& Reid, Note 2) but extended to accommodate the deprivation conditions of the present study. The seven categories were employed independently by two judges in the rating, with a reliability of $91.39 \%$ (Cicchetti, 1972). The seven categories ranging from most aware to least aware are defined as follows: (1) demand awareness or awareness of the experimental hypothesis; (2) evaluative awareness or awareness that left presses were followed by reinforcing or positive food words and right presses were followed by neutral words; (3) contingency awareness or awareness of being hungry or full, as well as that food words were presented on the left and neutral words on the right; (4) awareness of deprivation conditions and food words or awareness of a food-word contingency; (5) contingency search or trying to figure out the contingencies; (6) awareness of food words; and (7) no comments indicating awareness. Twenty-one subjects were demand, evaluative, or contingency aware and were excluded from consideration in the results. A chi-square 
test for two independent samples was performed on the frequency scores of the seven categories for the deprived and nondeprived groups. The results indicated no significant differences between groups in regard to awareness $\left[\chi^{2}(4)=8.61\right]$.

\section{DISCUSSION}

The present experiment adds to the support of the threefunction learning theory. The stimuli employed (food words) had previously been found to elicit an emotional response (Staats \& Hammond, 1972) and to be able to transfer this property in classical conditioning (Staats et al., 1972). The stimuli had also been found to serve an incentive function and elicit approachinstrumental behavior (Staats \& Warren, 1974). The present study showed that such stimuli also had reinforcing value, when the subjects had been deprived of food, as in the other studies. The several studies demonstrated that the emotion-liciting, reinforcing, and directive (incentive) functions of positive emotional stimuli are affected by deprivation-satiation operations. A variable that affects one stimulus function affects the others, showing the interrelationships of the functions and thus the interrelationship of Pavlovian and instrumental conditioning. This supports the contention that the operant concept of the reinforcing stimulus is oversimplified and should rather include the other two functions (Staats, 1975).

These findings, it may be added, provide a basis for stipulating the concept of motivation in the three-function learning theory. Classic accounts of two-process learning (Rescorla \& Solomon, 1967) have been criticized for not stipulating motivation principles (Trapold \& Overmier, 1972). The studies in the series that has been described indicate that deprivation of the primary emotion-eliciting stimulus (food) enhances the three stimulus functions of its associated stimulus, and this defines the motivational state involved and the motivational principles. A full theory of motivation involving these principles has been presented (Staats, 1968, 1975), and the theory has many implications for research.

It may also be noted that this series of studies supports the possibilities of studying basic conditioning principles employing human subjects. In the present case, the analysis of language learning suggested that there are classical conditioning principles involved for certain classes of words. The theoretical analysis enabled several experimental hypotheses to be derived, capable of basic experimental test. In the present study, an effect was shown that is analogous to drive effects on conditioned reinforcement in the animal laboratory, a principle that in the animal laboratory is not always easy to demonstrate. Centrally, the three-function learning theory was formulated to have theoretical value in the field of animal learning (see Staats, 1975; Staats \& Warren, 1974), and this should not be hidden by the theory's many human level extensions.

Finally, a word should be said concerning the significance of the several findings for understanding important characteristics of language. There are many emotion-eliciting words in natural language, both individual words and combinations of words. Such words can elicit physiological emotional response and can be expected to have conditioned stimulus value, reinforcing value, and directive stimulus value in influencing human behavior. These are some of language's most powerful functions, which give humans some of their unique characteristics in affecting each others' behavior. These functions can be affected by deprivation conditions. Further study of these functions is called for. words and some correlated associative properties (Tech. Rep. 3). Knoxville, Tenn: University of Tennessee, 1965.

2. Staats, A. W., Higa, W. R., \& Reid, I. E. Names as reinforcers: The social value of verbal stimuli (Tech. Rep. 9). Honolulu: University of Hawaii, Contract N00014-67-C-0387-0007, Office of Navy Research, 1970.

\section{REFERENCES}

Brown, P. L., \& Jenkins, H. M. Auto-shaping of the pigeon's key peck. Journal of the Experimental Analysis of Behavior, $1968,11,1-8$.

Cicchetri, D. V. A new measure of agreement between rank-ordered variables. Proceedings of the 80th Annual Convention of the American Psychological Association, 1972, 7, 17-18.

Finch, G. Hunger as a determinant of conditional and unconditional salivary response magnitude. American Journal of Physiology, 1938, 123, 379-382.

Finley, J. R., \& StAats, A. W. Evaluative meaning words as reinforcing stimuli. Journal of Verbal Learning and Verbal Behavior, 1967, 6, 193-197.

Holland, I. G., \& Skinner, B. F. The analysis of behavior. New York: McGraw-Hill, 1961.

Hull, C. L. Principles of behavior. New York: AppletonCentury-Crofts, 1943.

Rescorla, R. A., \& Solomon, R. L. Two-process learning theory: Relationships between Pavlovian conditioning and instrumental learning. Psychological Review, 1967, 74, 151-182.

SkINNER, B. F. The behavior of organisms. New York: Appleton, 1938.

StaATs, A. W. Social behaviorism and human motivation: Principles of the attitude-reinforcer-discrimination system. In A. C. Greenwald, T. C. Brock, \& T. M. Ostrom (Eds.), Psychological foundations of attitudes. New York: Academic Press, 1968.

StaAts, A. W. Social behaviorism. Homewood, Ill: The Dorsey Press, 1975.

StaAts, A. W., \& Hammond, O. W. Natural words as physiological conditioned stimuli: Food-word-elicited salivation and deprivation effects. Journal of Experimental Psychology, 1972, 96, 206-208.

Staats, A. W., Minke, K. A., Martin, C. H., \& Higa, W. R. Deprivation-satiation and strength of attitude conditioning: A test of attitude-reinforcer-discriminative theory. Journal of Personality and Social Psychology, 1972, 24, 178-185.

StaAts, A. W., \& Warren, D. R. Motivation and threefunction learning: Deprivation-satiation and approachavoidance to food words. Journal of Experimental Psychology, 1974, 103, 1191-1199.

Trapold, M. A., \& Overmier, J. B. The second learning process in instrumental learning. In A. H. Black \& W. F. Prokasy (Eds.), Classical conditioning, II. New York: Appleton-Century-Crofts, 1972.

Trapold, M. A., \& Winokur, S. W. Transfer from classical conditioning and extinction to acquisition, extinction, and stimulus generalization of a positively reinforced instrumental response. Journal of Experimental Psychology, 1967, 73, 517-525.

Zimmerman, D. W. Durable secondary reinforcement: Method and theory. Psychological Review, 1957, 64, 373-383.

\section{REFERENCE NOTES}

